Humanistika: Jurnal Keislaman

Vol. 3 No 1 2020. Hal. 75-99 ISSN (Print): 2460-5417 ISSN

(Online): 2548-4400

DOI: https://doi.org/10.36835/ humanistika.v8i1.763

\title{
Membumikan Akidah Melalui Syi'ir: Study Nilai-Nilai Akidah dalam Syi'ir Jama'ah Shalawat Nariyah Walisongo Desa Moncek Timur Lenteng Sumenep Madura
}

\author{
Miftahul Arifin \\ Universitas Islam Zainul Hasan Genggong Probolinggo \\ M42arivin@gmail.com
}

\begin{abstract}
This article describes the values of faith on syi'ir-syi'ir of Jama'ah Shlawat Nariyah Walisongo, East Moncek Village, Lenteng Sumenep, by KHR. Mubammad Kholil As'ad Syamsul Arifin, Caretaker of the Walisongo Islamic Boarding School, Mimbaan, Situbondo. Using a socio-histrosis approach, this article identifies the history of the founding of the Jama'ah History of Shalawat Nariyah Walisongo, East Moncek Village. The values of the faith contained in the syi'ir were analyzed using the theory of the main points of the Islamic faith. The results of the study show, first, that the history of the establishment of the Jama'ah Shlawat Nariyah Walisongo, East Moncek Village is quite unique. Unlike the congregations in general, the Jama'ah Shalawat Nariyah Walisongo was originally established specifically for people who were looked down upon morally, namely people who had the habit of stealing. However, the chanting of syi'ir-syi'ir accompanied by the rhythm of music became a new nuance in the midst of the East Moncek community. This congregation also attracted the attention of the general public to join as members of the congregation. Second, the syi'ir-syi'ir of Jama'ah Shalawat Nariyah Walisongo contains very high religious values, including values that are the basic foundation of Islam. These creed values include faith in Allah, faith in angels, faith in the Qur'an, and faith in the Prophet Muhammad and the apostles. At the Jama'ah Shalawat Nariyah in East Moncek Village, these values are absorbed in a more relaxed atmosphere through the activities of the Jama'ah Shalawat Nariyah Walisongo.
\end{abstract}

Keywords: Poem, Islamic Faith, Jama'ah Shlawat Nariyah Walisongo

https:// ejournal.unzah.ac.id/index.php/humanistika 


\title{
Miftahul Arifin
}

\begin{abstract}
Abstrak
Artikel ini menguraikan nilai-nilai akidah dalam syi'ir-syi'ir Jama'ah Shlawat Nariyah Walisongo Desa Moncek Timur Lenteng Sumenep karangan KHR. Muhammad Kholil As'ad Syamsul Arifin, Pengasuh Pondok Pesantren Walisongo, Mimbaan, Situbondo. Dengan menggunakan pendekatan sosio-histrosis artikel ini mengidentifikasi sejarah berdirinya Jama'ah Sejarah Shalawat Nariyah Walisongo Desa Moncek Timur. Nilai-nilai akidah yang terkandung dalam syi'ir tersebut dianalisa menggunakan teori pokok-pokok akidah Islam. Hasil penelitian menunjukkan, pertama, sejarah berdirinya Jama'ah Shlawat Nariyah Walisongo Desa Moncek Timur cukup unik. Tidak seperti jama'ah-jama'ah pada umumnya, Jama'ah Shalawat Nariyah Walisongo mulanya didirikan secara khusus bagi masyarakat yang dipandang rendah secara moral, yaitu masyarakat yang memiliki kebiasaan mencuri. Namun, lantunan-lantunan syi'ir-syi'ir yang diringi irama musik menjadi nuasa baru di tengah-tengah masyarakat Moncek Timur. Jama'ah ini pun menyedot perhatian masyarakat umum untuk bergabung menjadi anggota jama'ah. Kedua, syi'ir-syi'ir Jama'ah Shalawat Nariyah Walisongo memuat nilai-nilai keagaman yang sangat tinggi, termasuk nilai-nilai yang menjadi pondasi dasar agama Islam. Nilai-nilai akidah tersebut meliputi keimanan kepada Allah, keimanan kepada malaikat, keimanan kepada kitab Al-Qur'an, dan keimanan kepada Nabi Muhammad dan para rasul. Pada Jama'ah Shalawat Nariyah Desa Moncek Timur, nilai-nilai tersebut diserap dalam nuansa yang lebih santai melalui kegiatan Jama'ah Shalawat Nariyah Walisongo.
\end{abstract}

Kata Kunci : Syi'ir, Aqidah Islam, Jama'ah Shalawat Nariyah Walisongo. 
Membumikan Akidah Melalui Syi'ir: Study Nilai-Nilai Akidah dalam Syi'ir Jama'ah Shalawat Nariyah Walisongo Desa Moncek Timur Lenteng Sumenep Madura

\section{PENDAHULUAN}

Islam dan tauhid adalah dua entitas yang tidak dapat dipisahkan. Tidak ada satupun perintah dalam islam yang bisa dilepaskan nilai-nilai ketuhanan. Keyakinan dalam beragama, kewajiban manusia menyembah Allah yang diwujudkan melalui pelaksanaan perintah dan menjahui larangannya akan hancur jika melanggar tauhid. ${ }^{1}$ Tauhid menjadi dasar bagi orang beragama khususnya agama islam. Melanggar tauhid berarti beragukan bahwa Allah adalah satu-satunya tuhan yang berarti pula meyakini adanya wujud-wujud lain selain Allah sebagai Tuhan. ${ }^{2}$

Untuk memberikan keyakinan yang utuh akan adanya Allah, diturunkanlah Al Qur'an sebagai pedoman bagi umat manusia untuk bertauhid dan ber-islam yang benar dan menanamkannya ke dalam jiwa dalam kehidupan sehari-hari. Menurut Nasruddin Razak, Al Qur'an sebagai dasar utama dalam setiap tindakan manusia menunjukkan bahwa islam tidak dapat menemukan jalannya kedalam lubuk hati dan pikiran tanpa penerimaan dua cabang utama, yaitu iman dan syari'ah. Yang pertama diwajibkan oleh islam adalah adanya kepercayaan kepada Allah tanpa keraguan dan kesangsian dalam diri manusia. ${ }^{3}$ Bentuk kepercayaan itu kemudian diaplikasikan dalam bentuk sesembahan kepada Allah dengan cara menjalankan perintah dan menjahui larangan Allah. Allah Berfirman: "Aku tidak menciptakan jin dan

\footnotetext{
${ }^{1}$ Ismail Raji Al Faruqi, Taubid, terj. Rahmani Astuti, (Bandung: Penerbit Pustaka, 1988), 17

2 Ismail Raji Al Faruqi, Tabuid,...,17 2009, 1

${ }^{3}$ Dikutip oleh Daryanti, Jama'ah Pengajian Selapan Dusun Ngoloyo Trimulyo, Kendal (Tinjauan),
} 


\section{Miftahul Arifin}

manusia kecuali untuk menyembahku”. Ayat ini menjadi dasar tujuan penciptaan manusia yaitu untuk menyembah. Menyembah dalam arti menjalankan perintah dan menjahui larangan. Inilah esensi dari seluruh risalah Nabi Muhammad yang hampir tidak dapat terungkapkan oleh Nabi kecuali dalam kata-kata tuhan sendiri. Bahwa tauhid adalah perintah tuhan yang tertinggi dan terpenting dibuktikan dengan kenyataan adanya janji tuhan untuk menyampuni semua dosa kecuali pelanggaran terhadap tauhid. ${ }^{4}$ Inilah aqidah islam yang sesungguhnya.

Sayyid Sabiq mengatakan, tujuan yang utama adalah mendidik manusia menempuh jalan kehidupan dengan menyucikan jiwa serta mengarahkan untuk mencapai puncak dari sifat-sifat yang tinggi dan luhur serta lebih utama mengusahakan agar sampai pada tingkatan ma'rifat yang lebih tinggi. ${ }^{5}$

Dari pemaparan di atas dapat ditarik sebuah kesimpulan bahwa adalah dasar dari agama islam yang harus dimiliki oleh pemeluknya. Keyakinan akan adanya tuhan kemudian diaplikasikan dalah kehidupan sehari-hari dalam bentuk perbuatan baik yang sesuai dengan norma dalam islam, baik norma sosial maupun norma hukum yang berlaku. Keyakinan akan adanya tuhan tidak cukup tanpa ada reaksi positif yang ditampilkan secara nyata dalam laku kehidupan sehari-hari.

\footnotetext{
${ }^{4}$ Ismail Raji Al Faruqi, Taubid,...., 17

5 Sayyid Sabiq, Aqidah Islam, (Bandung: CV Diponegoro, Bandung, 1992), 19
} 
Membumikan Akidah Melalui Syi'ir: Study Nilai-Nilai Akidah dalam Syi'ir Jama'ah Shalawat Nariyah Walisongo Desa Moncek Timur Lenteng Sumenep Madura

Islam sebagai agama tauhid mengajarkan keimanan kepada Allah sebagai hal yang pokok dan utama. Kemudian diikuti pokok-pokok yang lain yang tidak bisa ditinggalkan. Pokok-pokok ajaran itu meiputi iman kepada malikat-malaikat Allah, kitab-kitab Allah, para rasul, hari akhir dan Qadla' dan Qadhar ${ }^{6}$ Allah yang kemudian dikenal dengan rukun iman.

Salah satu bentuk manifestasi atau keyakinan di masyarakat ialah melalui tradisi-tradisi yang telah mengakar secara turun-temurun. Biasanya tradisi tersebut tidak lain berasal dari ajaran-ajaran agama yang dipeluk dan dituangkan dalam bentuk tradisi lokal. Misalnya, di Desa Muncek Timur Kecamatan Lenteng Kabupaten sumenep Madura Jawa Timur, terdapat sebuah jamaah shalawat yang bernama “Jama'ah Shalawat Nariyah Walisongo”. Jama'ah ini bertujuan untuk menanamkan nilai-nilai keagamaan, tak terkecuali nilai-nilai ketuhanan bagi anggota jamaah yang dilakukan dengan membaca Shalawat Nariyah dan syi'ir yang memiliki muatan keagamaan yang sangat tinggi dengan diiringi irama musik tardisional.

Shalawat merupakan ibadah yang paling mudah dilakukan dan memiliki beberapa hikmah dan keutamaan. Salah satu keutamaan shalawat ialah barang siapa saja yang membaca sekalipun tanpa khusyu' atau disertai dengan sikap riya' ujub dan takabbur, maka bacaan shalawatnya akan tetap diterima dan mendapatkan pahala. ${ }^{7}$ Shalawat atau syi ir yang diiringi irama

${ }^{6}$ Yunahar Ilyas, Kuliah Aqidah Islam, (Yogyakarta: LPPI, Yogyakarta, 1993), 9

${ }^{7}$ Ibid, h. 131 


\section{Miftahul Arifin}

tertentu akan menimbulkan emosi keagamaan. Sebagaimana dikatakan oleh filsuf Prancis Henri Bergson, musik dapat menggugah emosi dalam hati manusia dan mengantarkan manusia untuk bertindak secara moral. ${ }^{8}$ Sehingga penanaman nilai-nilai keagamaan melalui Jamaah Shalawat Nariyah Walisongo di desa Moncek Timur boleh dikatakan efektif dengan alasan: pertama, tidak terlalu repot dalam mempraktekkan ajaran agama. Kedua, mendorong adanya emosi kegamaan. Ketiga, tersebut mudah diterima oleh anggota jamaah dan memiliki dampak psikologis bagi mereka yang notabene memiliki faham keagamaan yang rendah. Hal ini dimaksudkan sebagai upaya pembetukan moral secara bertahap.

Dakwah dalam islam sejatinya harus juga memperhatikan keadaan sosial. Dalam perspektif historis, pergumulan dakwah islam dengan realitas sosio-kultural akan menjumpai dua kemungkinan sebagaimana dikatakan oleh Safrodin Halimi. ${ }^{9}$ Pertama, dakwah mampu memberi hasil pada lingkungan dalam arti memberi dasar filosofi, arah, dorongan dan pedoman perubahan masyarakat sampai terbentuknya realitas sosial baru. Kedua, dakwah islam dipengaruhi oleh perubahan masyarakat dalam arti eksistensi, corak dan arahnya. Ini berarti bahwa aktualitas dakwah ditentukan oleh sistem sosio-kultural. Bagaimana cara berdakwah seseorang keberhasilannya sangat ditentukan cara ia berdakwah.

\footnotetext{
${ }^{8}$ Djuretna A. Imam Muhni, Moral dan Religi, (yogyakarta: Kanisius, 1994), 95

9 Safrodin Halimi, Etika Dakwah Dalam Perspektif Al Qur'an, Antara Realititas Qur'ani dan Realitas Sosial, (Semarang: Walisongo Press, 2008), 99.
} 
Membumikan Akidah Melalui Syi'ir: Study Nilai-Nilai Akidah dalam Syi'ir Jama'ah Shalawat Nariyah Walisongo Desa Moncek Timur Lenteng Sumenep Madura

Penanaman nilai-nilai kegamaan menggunakan syi'ir seperti yang diterapkan oleh Jamaah Shalawat Nariyah Walisongo telah banyak dilakukan oleh para ulama dan kyai terdahulu terutama meraka yang menganu faham Ablussunnab Waljamaah. Pada masyarakat Jawa zaman dulu misalnya, Syïiran menjadi sarana sosialisasi dan transmisi ajaran yang sangat efektif. Sebagai bagian dari kesenian, Syi'iran banyak disukai oleh masyarakat. Hal ini terbukti dengan penggunaanya secara luas di berbagai daerah yang bertempat di musholla dan masjid atau yang ditembangkan dalam berbagai acara sosial keagamaan. ${ }^{10}$

Oleh karena itu, artikel yang merupakan rinkasan dari penelitian penulis berjudul "Religious Values on Jama'ah Shalawat Nariyah Walisongo in Moncek Timur Lenteng Sumenep Madura" ini akan membahasa dua hal: pertama, tinjauan sosial historis berdirinya Jama'ah Shlawat Nariyah Walisongo di Desa Moncek Timur. Kedua, nilai-nilai yang terkandung dalam Syi'ir Jama'ah Shalawat Nariyah Walisongo Desa Moncek Timur.

\section{METODE PENELITIAN}

Jenis penelitian ini adalah penelitian lapangan (Field Research), yaitu penelitian yang dilakukan dalam realitas sebenarrya. Berupa, pengumpulan data yang dilakukan dengan meneliti di tempat terjadinya gejala yang diteliti. Metode pengumpulan data dilakukan dengan wawancara dan mengumpulkan dokumen-dokumen untuk memperoleh pengetahuan atau

${ }^{10}$ Muhsin Jamil, Syi'iran Transmisi Ajaran Islam di Jawa, (Semarang: Walisongo Press, 2010), 4 Humanistika: Vol.8 No 12022 


\section{Miftahul Arifin}

informasi secara mendalam mengenai Jama'ah Shalawat Nariyah Walisongo dan syi'ir-syi'ir yang digunakan.

Adapun sumber sumber data meliputi Sumber Primer, yaitu sumber data secara langsung ${ }^{11}$ yang diperoleh dari ketua jamaah, anggota yang berpengalaman mengenai Jamaah Shalawat Nariyah Walisongo dan syiłirsyi'ir-nya dan Sumber Sekunder yang diperoleh atau mengutip dari bukubuku yang berkaitan. ${ }^{12}$

Dalam mengalisis data-data yang telah diperoleh dari perpustakaan atau data lapangan penulis menggunakan Metode kualitatif, yaitu prosedur penelitian yang menghasilkan data deskriptif berupa kata-kata tertulis atau lisan dari orang-orang dan perilaku yang diamati. ${ }^{13}$ Analisis deskriptif digunakan untuk menemukan pengetahuan yang sekuas-luasnya terhadap objek penelitian. Sebagaimana dijelaskan Punaji Setyosari, penelitian deskriptif adalah penelitian yang bertujuan untuk menjelaskan atau mendeskripsikan suatu keadaan, peristiwa, objek apakah orang, atau segala sesuatu yang terkait dengan variabel-variebel yang bisa dijelaskan baik dengan angka-angka maupun kata-kata.

Pada penelitian terhadap Syi'ir Jamaah Shalawat Nariyah Walisongo di Desa Moncek Timur, peneliti berusaha mengumpulkan Syi’ir yang dipakai 1980), 134

11 Winarno Surahmad, Pengantar Penelitian Ilmiah (Dasar Metode Teknik), (Bandung: Tarsito,

12 Ibid, h. 135

13 Moleorg J. Lexy, Metode Penilitian Kualitatif dan Kuantitatif, (Bandung: Remaja Rosdakarya, 2000), 3 
Membumikan Akidah Melalui Syi'ir: Study Nilai-Nilai Akidah dalam Syi'ir Jama'ah Shalawat Nariyah Walisongo Desa Moncek Timur Lenteng Sumenep Madura

oleh jamaah tersebut untuk kemudian dijelaskan secara deskriptif sesuai dengan arah penelitian ini. Yaitu, penelitian terhadap latar belakang berdirinya jama'ah nilai-nilai aqidah yang terdapat pada syi'ir tersebut. Pada bagian lata belakang, penulis menggunakan sosio-historis sebagai pisau analisis. Sedangkan pada bagian aqidah, penulis menggunakan teori pokokpokok islam.

\section{HISTORISITAS JAMA'AH SHALAWAT NARIYAH WALISONGO DESA MONCEK TIMUR}

a. Sejarah Jama'ah Shalawat Nariyah Walisongo Desa Moncek Timur

Secara historis, berdirinya Jama'ah Shalawat Nariyah Walisongo di Desa Moncek Timur Kecamatan Lenteng Kabupaten Sumenep tidak bisa dilepaskan dari asal-usul berdirinya Jamaah Shalawat Nariyah Walisongo di Desa Errabu Kecamatan Bluto Kabupaten Sumenep yang secara georafis kedua desa ini bersebelahan. Bahkan bisa dikatakan bahwa jama'ah di Desa Moncek adalah cabang atau pentolan dari jamaah di Desa Errabu walaupun memiliki latar belakang yang berbeda.

Berdirinya Jamaah Shalawat Walisongo di Desa Errabu berawal dari kedatangan KHR. Muhammad Kholil As'ad Syamsul Arifin, Pengasuh Pondok Pesantren Walisongo, Situbondo, di Pondok Pesantren Mashlahatul Hidayah Desa Errabu untuk mengisi pengajian umum tahun 2009. Kiai Kholil yang datang bersama rombongan musik tradisional yang mengiringinya disela-sela berceramah memberi kesan tersendiri bagi masyarakat Errabu dan sekitarnya. Terbukti setelah beliau pulang ke 


\section{Miftahul Arifin}

kediamannya di Situbondo, amalan shalawat nariyah dan syïir serta musik tradisional tetap membekas dan menjadi salah satu tradisi keagamaan masyarakat. Kegiatan tersebut diberi nama Jama'ah Shalawat Nariyah Walisongo yang diprakarsai oleh K.Nor Kholis, salah satu tokoh agama dan masyarakat di Desa Errabu. Pada awalnya tidak lebih dari 15 orang yang bergabung dengan jama;ah ini. Namun seiring berjalannya waktu, keanggotaan anggota terus bertambah, bahkan tidak sampai satu tahun terhitung ada 101 orang.

Respon masyarakat terhadap Jamaah Shalawat Nariyah Walisongo tidak hanya oleh masyarakat Errabu. Beberapa kelompok masyarakat di daerah Sumenep juga antusias dengan jamaah ini. Terbukti, sedikitnya ada 19 kelompok Jamaah Shalawat Nariyah Walisongo yang tersebar diberbagai daerah di Kabupaten Sumenep seperti, Desa Lobuk, Sumenep Kota, Desa Gaddu, Desa Kalianget dan dan lain-lain. Seperti jamaah di desa Errabu, mereka juga menggunakan musik untuk mengiringi Syi'ir.

Jamaah Shalawat Walisongo di Desa Moncek Timur berdiri pada tanggal 27 Desember 2010 yang diprakarsai salah sau warga bernama Maskur. Latar belakang jama'ah ini cukup unik. Pasalnya, Maskur adalah seorang mantan bejingan. ${ }^{14}$ Maskur pernah mendekam selama 5 tahun di penjara karena kasus pencurian ternak. Maskur akhirnya insaf dan meninggalkan profesinya sebagai maling. Pendirian Jama'ah Shalawat

${ }^{14}$ Bejingan atau Bejing adalah sebutan untuk penjahat atau maling yang biasa digunakan oleh masyarakat Moncek dan sekitarnya.

Humanistika: Vol.8 No 12022 
Membumikan Akidah Melalui Syi'ir: Study Nilai-Nilai Akidah dalam Syi'ir Jama'ah Shalawat Nariyah Walisongo Desa Moncek Timur Lenteng Sumenep Madura

Walisongo berawal instruksi K. H. Hasan, tangan kanan K. HR. Kholil As'ad Syamsul Arifin. Bermula dalam satu kesempatan ketika K. Hasan mendampingi K. Kholil mengikuti sema'an Al Qur'an di rumah salah satu tokoh masyarakat sebuah desa yang tak jauh dari Desa Moncek. Maskur yang juga ikut dalam acara tersebut tiba-tiba dipanggil K. Hasan dan diperintahkan mendirikan Jama'ah Shalawat Nariyah Walisongo Lengcellengngah ${ }^{15}$. Maskur sempat kaget. Disamping ia merasa tidak pantas, keduanya memang belum saling mengenal. Singkat cerita, Maskur memenuhi permintaan K. Hasan.

Maskur mengadakan musyawarah dengan menghimpun beberapa orang dari berbagai pihak, mulai dari orang biasa, tokoh masyarakat, kiai beberapa bejingan yang merupakan kawan seperjuangannya dulu ketika belum insaf. Musyawarah berlangsung di rumah Maskur dengan kesepakatan akhir yaitu terbentuknya jamaah. Jamaah Shalawat Nariyah Walisongo Desa Moncek Timur kemudian diresmikan pada tanggal 15 Januari 2011. Lima hari sebelum itu, tanggal 10 Januari 2011 hasil musyawarah disampaikan pada K. H. Hasan untuk disampaikan kepada K. HR. As'ad Syamsul Arifin. Dikabarkan, K. HR Kholil sangat berbahagia dengan menampakkan wajah berseri-seri.

${ }^{15}$ Leng-cellengah berasal dari bahasa madura yang berarti “hitam”. Penyebutan ini dimaksudkan untuk mempertegas bahawa Jamaah Shalawat yang ada di Moncek Timur merupakan jamaah yang dikhususkan untuk orang-orang yang bergelut di dunia hitam. Yang pertama kali menyebut nama itu ialah K. H. Hasan Ketika memerintahkan kepada Maskur untuk mendirikan jamaah. Namun, karena takut menyinggung para anggota jamaah, penyebutan itu dihilangkan dan diganti dengan Jamaah Shalalawat Walisongo malam minggu. 


\section{Miftahul Arifin}

Pada awalnya anggota jamaah hanya berjumlah 25 orang dengan kesepakatan dilaksanakan dua minggu sekali yaitu pada malam senin setelah adzan isya'. Namun, seiring berjalanya waktu, anggota jamaah semakin bertambah termasuk mereka yang bukan dari golongan pencuri juga ikut bergabung dengan jama'ah tersebut. Tahun 2015, anggota jamaah berjumlah 67 orang, terdiri dari masyarakat biasa dan bejingan. Saat ini, jumlah jama'ah mengalami penurunan, sekitar 50 orang. Penurunan disinyalir karena terbenturnya dengan aktivitas yang lain sehingga ada bebera anggota yang berhenti. ${ }^{16}$ Bergabungnya beberapa anggota masyarakat biasa ke dalam jama'ah karena senangnya terhadap shalawat dan syi'ir-syi'ir yang dilagukan disertai dengan iringan musik.

Daya tarik Jama'ah Shalawat Nariyah Walisongo tentu bisa dimengerti karena memberikan warna baru bagi masyarakat Moncek Timur. Iringan musik tradisional, disamping menjadi ciri khas tersendiri telah memberikan nuasa lebih santai dibanding dengan jama'ah-jama'ah lain yang umum diikuti oleh masyarakat Moncek Timur. Sebelum kedatangan K. Kholil, jama'ahjamaah keagamaan di Moncek Timur secara khusus dan Sumenep secara umum sangat jarang menggunakan musik. Bahkan sebagian masyarakat Moncek Timur meyakini bahwa musik haram, apalagi jika dicampuradukkan dengan kegiatan keagamaan. Kedatangan K. Kholil dengan alat-alat

${ }^{16}$ Muhammad Naufal, salah satu anggota Jama'ah Shlawat Nariyah Walisongo. Wawancara 15 Januari 2021. 
Membumikan Akidah Melalui Syi'ir: Study Nilai-Nilai Akidah dalam Syi'ir Jama'ah Shalawat Nariyah Walisongo Desa Moncek Timur Lenteng Sumenep Madura

musiknya ke Sumenep memberikan perubahan besar terhadap cara pandang masyarakat terhadap musik itu sendiri.

Secara sosiologis, masyarakat memang sudah terbiasa dengan mengikuti jama'ah-jama'ah atau perkumpulan-perkumpulan yang biasa dikenal dengan istilah kompolan. Kompolan bagi masyarakat Madura adalah bagian dari tradisi. Tradisi kompolan merupakan pertemuan keagamaan antara sesama laki-laki atau sesama perempuan. Kompolan dilaksanakan secara bergiliran dari satu rumah jama'ah ke rumah jama'ah lainnya. ${ }^{17}$ Kompolan bagi masyarakat Madura senantiasa berkaitan dengan ekspresi keagamaan yang dilakukan secara berkelompok. Selain itu, agama dipahami sebagai bagian dari kehidupan masyarakat Madura sehingga kompolan yang berorientasi pada nilai dan ajaran keagamaan menjadi bagian yang tidak terpisahkan dari keseharian. ${ }^{18}$ Dengan ini dapat dimengerti bahwa hadirnya Jama'ah Shalawat Nariyah Walisongo akan dengan mudah diterima dengan baik oleh masyarakat Moncek Timur. Terlebih Jama'ah Shalawat Nariyah bisa memberikan nuasa baru dalam proses tranformasi nilai-nilai keagamaan bagi masyarakat dimana musik dan syi'ir-syi'ir menjadi bagian yang tidak terpisahkan.

b. Pelaksanaan dan Amalan

${ }^{17}$ Tatik Hidayati, Kompolan: Kontestasi Tradisi Perempuan Madura, Jurnal KARSA, Vol. 19 No. 2 Tahun 2011, 149

${ }^{18}$ Ibid 


\section{Miftahul Arifin}

Kegiatan Jamaah Shalawat Nariyah Walisongo berlangsung secara rutin setiap dua minggu sekali, tepatnya Selasa Malam atau Malam Rabu setelah isyak. Pelaksanaan dikemas secara sederhana seperti kebanyakakan perkumpulan yang ada di Desa moncek Tumur dan sekitarya. Yang sedikit membedakan dengan perkumpulan lain ialah, Jamaah Shawalat Walisongo menggunakan pengeras suara berupa beberapa unit sound system. Hal tersebut bertujuan agar bacaan-bacaan sholawat dan syair-syair dapat dinikmati oleh masyarakat, tidak hanya anggota jamaah. Dengan pengeras suara diharapkan, masyarakat yang tidak bergabung bisa juga bisa mengkaji nilainilai yang terkandung dalam syi'ir untuk kemudian menjadi pegangan hidup dan menjadikan desa Moncek Timur lebih kental dengan nuasa religius.

Secara teknis, pelaksnaan Jamaah Shalawat Nariyah Walisongo dapat dibagi ke dalam enam tahap: pertama, pembukaan. Jamaah dibuka dengan Sholawat dan pembacaan syi'ir khusus pembukaan yang diiringi dengan musik. Penanggap jamaah atau yang dikenal dengan tuan rumah berdiri di depan pintu atau halaman untuk menyambut datangnya anggota jamaah yang lain. Anggota jamaah yang datang menempati tempat yang sudah disediakan oleh tuan tumah. Kedua, Pembacaan surat al-Fatihah dan tawashul khusus yang dipimpin langsung oleh kyai. Tawashul di sini berupa pembacaan surat al fatihah yang dihadiahkan kepada nabi Muhammad, ulama, para wali dan sesepuh-sesepuh yang telah lebih dahulu wafat. Kemudian dilanjutkan dengan khataman Sholawat Nariyah, yaitu sebanyak 4444 (empat ribu empat ratus empat puluh empat) kali dengan 
Membumikan Akidah Melalui Syi'ir: Study Nilai-Nilai Akidah dalam Syi'ir Jama'ah Shalawat Nariyah Walisongo Desa Moncek Timur Lenteng Sumenep Madura

menggunakan biji saga sebagai alat hitung yang dibagikan ke seluruh anggota jamaah. Pada tahapan ini anggota jamaah yang dipandu langsung oleh kyai terlihat sangat khusyu' membaca sholawat. Setelah selesai membaca Shalawat Nariyah dilangsung dengan pembacaan Shalawat julus pertama. ${ }^{19}$

Ketiga, Shalawat qiyam ${ }^{20}$. Pada kesempatan ini, seluruh anggota jamaah berdiri membaca sholawat kepada Nabi Muhammad yang diikuti juga dengan pembacaan syi'ir. Prosesi berdiri ini sebagai bentuk penghormatan kepada Namu Muhammad. Sebagaimana kita ketahui, berdasarkan pendapat beberapa ulama, bahwa Nabi Muhammad menghadiri satu kelompok yang membacakan sholawat untuk beliau. Hal ini juga diyakini oleh masyarakat Moncek Timur khususnya anggota Jamaah Shalawat Walisongo.

Keempat, pembacaan doa khusus yang dipimpin langsung oleh kyai. Setelah pembacaan doa selesai istirahat sejenak untuk kemudian dilanjutkan ke tahapan berikutnya. Bebas melakukan apa saja dengan catatan tidak melanggar etika kesopanan yang berlaku.

Kelima, Sholawat julus ${ }^{21}$ kedua atau sholawat julus akhir. Tahapan ini merupakan tahapan akhir sebelum penutup dalam prosesi pelaksanaan

${ }^{19}$ Shalawat julus ialah shalawat yang dilakukan dengan duduk bersila sebagai pengantar untuk Shawalat Qiyam. Pada tahapan ini juga membaca syi'ir-syi'ir karangan K. HR. As'ad Syamsul Arifin 23 bait

${ }^{20}$ Qiyam berasal dari bahasa arab yang berarti berdiri.

${ }^{21}$ Kata julus berasal dari bahasa arab yang berarti duduk. Shalawat julus berarti pembacaan shalawat dan syi'ir yang dilakukan dengan cara duduk. Dalam prosesi duduk ini, Jamaah Shlawat Nariyah Walisongo melakukannya dengan cara duduk bersila. 


\section{Miftahul Arifin}

Jamaah Shalawat Walisongo. Di sini pula puncak pembacaan syi'ir KHR. As'ad Syamsul Arifin dikumandangkan oleh anggota jamaah dengan tetap diiringi oleh irama musik tradisional. Dengan khusyu' dan secara seksama anggota jamaah membaca sholawat dan syii ir tersesebut, bergantian dengan kyai atau orang tertentu yang biasa mendampingi kyai. Beberapa syi'ir dibacakan sampai menjelang larut malam. Anggota jamaah terlihat menikmati syi'ir-syi'ir yang mengandung nila-nilai kegamaan tersebut. Setelah pembacaan syi'ir selesai, prosesi dilangsungkan dengan doa yang dipimpin langsung oleh kyai.

Keenam, penutup. Prosesi pelaksaan Jamaah Shalawat Nariyah Walisongo ditutup juga dengan pembacaan sholawat dan syi'ir khusus yang berisi ucapan terima kasih kepada tuan rumah. Syi'ir tersebut dibaca secara rutin setiap kali pelaksanaan. Pada sesi ini anggoita jamaah sudah siap-siap untuk kembali ke rumah masing-masing.

c. Syi'ir

Sebanyak 41 syi'r yang dibaca secara rutin oleh angota Jama'ah Shalawat Nariyah Walisongo. Ke 41 syi'r tersebut tidak dibaca sekaligus pada saat pelaksanaan. Hal tersebut karena terbatasnya waktu mengingat jumlah syi'ir yang tidak sedikit. Namun demikian pengurus jamaah telah menentukan proses pembacaan syi'ir-syi'ir yang ada agar syi'ir dapat dibaca secara keseluruhan.

Syi'ir-syi'ir dalam Jamaah Shalawat Nariyah Walisongo di Desa Moncek Tumur merupakan kumpulan syïir karangan K. HR. Kholil As'ad 
Membumikan Akidah Melalui Syi'ir: Study Nilai-Nilai Akidah dalam Syi'ir Jama'ah Shalawat Nariyah Walisongo Desa Moncek Timur Lenteng Sumenep Madura

Syamsul Arifin Mimbaan Situbondo. Tidak ada kitab khusus mengenai kumpulan syi'ir tesebut. Menurut Ahmad Jauzi, syi'ir-syi'ir tersebut sampai kepada jamaah ini melalui catatan-catatan biasa atau rekaman yang diperoleh dari salah seorang yang memilki relasi ke tim yang biasa mencatatan syi'ir K. HR Kholil, dimana, beliau menciptakan syi'ir tersebut. K. HR. Kholil As'ad Syamsul Arifin merupakan ulama yang bisa dibilang produktif dalam menciptakan syi'ir. Ratusan syi'ir yang sudah beliau ciptakan yang meliputi berbagai tema seperti tauhid, tasawuf, kenabian, etika, kenegaraan, pengajaran dan lain-lain.

Akan tetapi, dari keseluruhan syi'ir tersebut belum ada yang dicetak di penerbit resmi untuk kemudian dijadikan kitab syi’ir. Akan tetapi hanya menggunakan catatan-catatan biasa dan rekaman-rekaman. Begitupun dengan syi'ir-syi'ir yang sampai kepada Jamaah Shalawat Walisongo di Desa Moncek Timur hanya sebagian, yang sampai melaui catatan dan rekaman yang kemudian dihafalkan hingga melekat di hati anggota jamaah. 
NILAI-NILAI DALAM SYI'IR-SYI'IR JAMA'AH SHALAWAT

NARIYAH WALISONGO DESA MONCEK TIMUR (1500-2500

WORDS)

Syi'ir dikenal juga syi’iran memang berasal dari kata syïir dan berakhiran -an. Kata syiłir berasal dari bahasa Arab yang dalam bahasa Indonesia diartikan dengan puisi, dan -an merupakan akhiran yang menunjukkan identitas ke-Jawaan. ${ }^{22}$ Syi'ir merupakan salah satu genre yang terdiri atas kata dan lagu yang beredar secara lisan di antara komunitas lokal Jawa yang berpusat di kampung-kampung. ${ }^{23}$ Pada masyarakat jawa, syi'ir menjadi alat sosialisasi ajaran Islam yang paling efektif karena melaui kesenian yang notabene banyak disukai orang. Puncak kejayaan Syi'iran di jawa adalah berkembangnya berbagai kesenian bernafaskan Islam pada jaman Wali Songo. Hingga kini syi'ir masih dikembangkan oleh kyai-kyai desa yang bebasis aliran Ablussunnah Waljamaah. ${ }^{24}$

Syi'ir dalam Jamaah Shalawat Nariyah Walisongo merupakan syi'ir karangan KHR. Muhammad As'ad Syamsul Arifin, pengasuh pondok pesantren Walisongo Mimbaan Situbondo. Digunakannya syi'ir-syi'ir K. Kholil tidak bisa dilepaskan juga dari latar belakang berdirinya jama'ah ini yang bisa dikatakan berkat kedatangan K. Kholil ke Desa Errabu jama'ah ini berdiri di Moncek Timur. Selain alim ilmu agama, K. Kholil juga dikenal

\footnotetext{
${ }^{22}$ Muhammad Muzakka Mussaif, Memanfaatkan Tradisi Lisan, 2008,7

${ }^{23}$ Aton Rustandi, Belajar dari Syi'iran: Art and Multicutural, (Semarang:Recent MediaYayasan Akar Rumput, 2007).

${ }^{24}$ M. Muhsin Jamil, Syi’iran dan Transmisi Ajaran Islam di Jawa ...,24-25
} 
Membumikan Akidah Melalui Syi'ir: Study Nilai-Nilai Akidah dalam Syi'ir Jama'ah Shalawat Nariyah Walisongo Desa Moncek Timur Lenteng Sumenep Madura

ahli ilmu kanuragan (ilmu kesaktian). Maka tidak heran jika murid-muridnya selain banyak dari santri pada umumnya juga banyak dari kalangan berandalan. K. Kholil juga membina anak jalanan yang disegani di Situbondo. ${ }^{25}$ Jamaah Sholawat Walisongo di Desa Moncek Timur tak lain juga termasuk binaan khusus yang sudah mendapatkan restu dari K. HR. As'ad Syamsul Arifin. Setiap tahun anggota Jama'ah Shlawat Nariyah Walisongo Desa Moncek Timur bisa dipastikan datang bersama-sama untuk sowan langsung ke K. Kholil untuk menyambung tali silaturrahmi dan berharap mendapat berkah dari K. Kholil. Kebiasaan sowan ini sudah berlangsung sejak dulu, sejak jama’ah ini berdiri sampai sekarang.

Syi'ir karangan K. Kholil jumlahnya cukup banyak. Namun yang populer dipakai Jamaah Shalawat Walisongo hanya 41 buah. Setiap syi'ir memiliki judul dan baris yang berbeda-beda. Hal tersebut berkaitan dengan makna dari masing-masing syi'ir tersebut. Ada yang jumlah barisnya ganjil, ada juga yang jumlah barisnya genap. Paling banyak terdapat pada syi'ir ke39: Hei Tang Abe', yaitu berjumlah 32 baris. Dan yang paling sedikit terdapat pada syi'ir ke-36: Amimpeh Kanjeng Nabi, yaitu hanya 4 baris.

Syi'ir Kiai Kholil memiliki kandungan yang beragam antara lain pujian kepada Nabi Muhammad, akhlak, nasionalisme, dan yang menjadi fokus kajian ini yaitu tentang. Syi'ir-syi'ir yang memiliki muatan dapat dijumpai dalam banyak syi'ir. Meminjam pengertian yang dikemukakan Dr.

${ }^{25}$ Lihat Majalah Nabdlatul Ulama, Aula edisi XXXVI Desember 2014, 27 


\section{Miftahul Arifin}

Shalih bin Fauzan dalam kitab At-Taubid Lish-Shaffil Awwal Al 'Aly ${ }^{26}$ bahwa berarti keimanan kepada Allah, iman kepada para Malaikat, iman kepada Kitab-kitab Allah, iman kepada para Rosul, iman kepada Hari Akhir dan Iman kepada Qadar Allah yang baik maupun yang buruk. Enam pokok tersebut merupakan satu kesatuan yang tidak akan berubah-ubah karena pergantian zaman atau tempat, tidak pula berganti karena perbedaan golongan atau masyarakat. ${ }^{27}$

Adapun nilai-nilai akidah dalam syi'ir K. Kholil yang dipakai Jama'ah Shalawat Nariyah Walisongo sebagai berikut:

Pertama, Iman kepada Allah. Iman kepada Allah ialah yakin bahwa Allah merupakan sembahan yang benar, hanya Allah yang berhak disembah, yakin bahwa Allah sebagai pencipta alam dan yang berkuasa atas segalanya. ${ }^{28}$ Syi'ir tentang Iman kepada Allah ini misalnya terdapat dalam syi'ir ke enam (6) yang berjudul Se Nyiptaaghi. Se Nyiptaaghi berasal dari bahasa Madura yang berarti "yang menciptakan". Kata ini ditujukan kepada Allah sebagai pencipta. Syi'ir ini mengandung ajaran tauhid berupa pengakuan atas ketuhanan Allah yang menciptakan segala sesuatu, Allah ialah pencipta alam, langit dan bumi, para Nabi, para Wali dan seluruh umat manusia. Sebagai orang yang beriman manusia diperintahkan untuk menyembah kepada

26 Ibid, 3

${ }_{27}$ Mohammad Abdai Rathomi, Aqidah Islam, Pola Hidup Manusia Beriman, terj. Assyyid Sabiq, Al-Aquidah Al-Islamiyah, (Bandung: Ikatan Penerbit Indonesia (IKPI), 1982), 17.

28 Syaikh Abdul Aziz bin Baaz, Shahibah Versus Aqidah Bathilah, (Riyadh:Kantor Dakwah Komplek Industri Lama, Riyadh 2002), 6 
Membumikan Akidah Melalui Syi'ir: Study Nilai-Nilai Akidah dalam Syi'ir Jama'ah Shalawat Nariyah Walisongo Desa Moncek Timur Lenteng Sumenep Madura

Allah. Dalam surat Az Zumar Allah swt berfirman: "Allab menciptakan segala sesuatu dan dia memelihara segala sesuatu” (Az Zumar: 62). Menurut Syaikh Abdul Aziz bin Baaz, Iman kepada Allah juga mencakup keyakinan terhadap semua yang diwajibkan oleh Allah kepada manusia yang tercakup dalam rukun islam. Laa Ilaha Illallah dalam syahadat bermakna pemurnian ibadah tertuju hanya kepada Allah semata dan penolakan terhadap sesembahan yang lain. ${ }^{29}$

Syi'ir yang berisi tentang pengakuan Allah sebagai pencipta juga terdapat pada syi'ir ke tiga puluh empat (34) Abhedhi abe'. Abhedhi abe' berarti "Mencipatakan diri (manusia)". Karena seluruh alam termasuk manusia merupakan ciptaan Allah maka kedudukan manusia dimuka bumi hanya numpang kepada Allah. Biar bagaimanapun Allah dengan sifat qudrat-Nya memiliki kuasa dan tiada larangan baginya untuk berbuat apapun sesuai dengan kehendaknya. Sedangkan manusia hanya makhluk yang lemah dan sejatinya tidak punya kekuasaan apapun.

Kedua, Iman kepada Kitab-Kitab Allah. Allah memerintahkan orang muknin untuk beriman kepada Allah dan apa yang telah diturunkan oleh Allah. Allah menurunkan kitab-kitab sebagai wahyu kepada Nabi agar menjadi tuntunan bagi manusia. Keimanan kepada kitab-kitab Allah berarti mengakui dan menyakini bahwa Allah menurunkan kitab untuk dijadikan pedoman bagi manusia. Sebagai umat Nabi Muhammad, beriman kepada

${ }^{29}$ Ibid, 10

Humanistika: Vol.8 No 12022 


\section{Miftahul Arifin}

kitab Allah secara khusus berarti mengimani Al Qur'an sebagai tuntunan bagi orang muslim yang diturunkan Allah kepada Nabi Muhammad.

Dalam syi’ir Jamaah Shalawat Walisongo keimanan kepada Al Qur'an dapat digambarkan dalam syi'ir ke dua puluh delapan (28) yang berjudul Mababbatul Qur'an. Syi'ir ini secara khusus berisi tentang namanama Al Qur'an beserta alasan Allah meberikan nama itu. Banyaknya nama Al Qur'an karena keagungan Al Qur'an itu sendiri serta hikmah yang terkandung di dalamnya. Al-Sayuthi mengatakan, fainna kasrat al-asma’ tadulla ala syarafi al-musamma. Maksudnya, sesungguhnya banyak nama itu mengisyaratkan kemuliaan sesuatu yang dinamai. ${ }^{30}$ Nama-nama al Qur'an sebagaimana syi'ir di atas ialah, An Nur, Hudan, Al-Syifa',Adz-Drikir dan AlRohmah.

Al Qur'an juga diberi nama An Nur karena dapat memberi penerang bagi pembaca, pengamal dan kepada segalanya. Penerang di sini bisa berarti petunjuk atau jalan yang dapat menuntun manusia ke arah yang benar, sesuai dengan jalan Allah. Sama halnya dengan alasan Al Qur'an diberi nama Hudan Ia bisa menjadi petunjuk ke jalan tuhan untuk mencapai ridho tuhan agar manusia sampai kepada tuhan. Al Qur'an juga diberi nama Al-Syifa', obat bagi seluruh orang mu'min khususnya obat dari penyakit yang ada di dalam dada manusia. Obat jiwa agar ia menjadi tenang dan tentram. Al Qur'an diberi nama Adz-Drikir sebagai alat untuk mengingatkan manusia kepada

${ }^{30}$ H. Muhammad Amin Suma, Ulumul Qur'an, (Jakarta: Rajawali Press, 2013), 32 
Membumikan Akidah Melalui Syi'ir: Study Nilai-Nilai Akidah dalam Syi'ir Jama'ah Shalawat Nariyah Walisongo Desa Moncek Timur Lenteng Sumenep Madura

ajaran-ajaran Allah yang dibawa oleh Nabi Muhammad. Al Qur'an akan mengingatkan manusia kepada perintah-perintah Allah beserta laranganlarangannya. Satu tujuan tak lain agar manusia bisa sampai kepada Tuhan. Al Qur'an juga diberi nama Al-Rohmat karena dengan Al Qur'an manusia bisa mengerti akan rahmat Tuhan. Karena rahmat ini pula tumbuhlah rasa kasih sayang antar sesama manusia. Keharmonisan yang terjadi antar umat manusia tak lain karena rahmat Tuhan yang diberikan kepada manusia melalui ajaran Al Qur'an. Al Qur'an adalah imam yang akan menuntun umat islam menuju Allah swt.

Ketiga, Iman kepada para Rosul yang tergambar dalam syi'ir keempat (4) berjudul Kebanggaan. Syi'ir di atas berisi tentang pengakuan dan kebanggaan orang mu'min (umat islam) kepada Nabi Muhammad sebagai Nabi penutup akhir zaman. Ia menjadi contoh bagi setiap orang mu'min yang ingin menuju tuhan. Paling tingginya derajat kenabian dari pada nabi yang lain disandarkan kepada Nabi Muhammad SAW. Nabi dalam syi'ir ini disebuat sebagai "Mahkota Para Nabi" yang dalam Kamus Besar Bahasa Indonesia $(\mathrm{KBBI})$ mahkota berarti hiasan kepala atau songkok kebesaran bagi seorang raja atau ratu. Mahkota disini menjadi simbol akan agungnya Nabi Muhammad, lebih agung dari pada nabi yang lain. Kebanggaan atas Nabi Muhammad menjadi bukti bahwa seseorang telah beriman kepada Nabi Muhammad. Kata "para" pada kalimat "Mabkota-mabkota para Nabi" menunjukkan sebuah pengakuan/keimanan akan adanya Nabi selain Muhammad. 


\section{Miftahul Arifin}

Nabi Muhammad juga digambarkan dalam syi'ir tersebut merupakan sosok yang memiliki akhlak yang sangat agung dan terpuji. Ia adalah panutan bagi setiap orang mu'min yang ingin mengabdi kepada Allah. Tidak dapat disangkal sejarah telah mencatat mengenai keagungan akhlak Rosulullah. Allah juga telah menjelaskan dalam Al Qur'an bahwa prilaku Rosulullah berdasarkan Al Qur'an. Sebagai orang mukmin wajib hukumnya mengimani para Rosul khususnya Nabi Muhammad sebagai Nabi penutup akhir zaman. Beriman kepada Rosulullah berarti mencintai Rosulullah. Orang yang sedang mencintai pasti ia akan selalu ingat orang yang dicintainya. Wujud cinta bisa dilakukan dengan selalu mengingat dan menyebut-nyebut namanya atau mendengarkan apa yang dikatakannya. Cinta kepada Rosulullah bisa diwujudkan dengan selalu menyebut namanya atau mengikuti ajaran-ajaran Rosulullah.

Keempat, Iman kepada Hari Akhir. Beriman kepada hari Akhir berarti percaya akan adanya kehidupan setelah kematian. Beriman kepada Hari Akhir mencakup keimanan terhadap datangnya kematian seperti firnah khubur, adzab atau nikmat-Nya. Hari kahir juga berkaitan dengan berita mengenai apa yang akan terjadi setelah hari kiamat misalnya syirat, Mizan, Hisab dan pemberian catatan amal. Keyakinan terhadap adanya Hari Akhir juga berkaitan dengan kepercayaan bahwa orang mukmin akan melihat Allah di akhirat, adanya surga dan neraka. ${ }^{31}$ Dalam syi'ir Jamaah

${ }^{31}$ Syaikh Abdul Aziz bin Abdullah bin Baaz, Shabihah Versus Aqidah Bathilah... 24 
Membumikan Akidah Melalui Syi'ir: Study Nilai-Nilai Akidah dalam Syi'ir Jama'ah Shalawat Nariyah Walisongo Desa Moncek Timur Lenteng Sumenep Madura

Shalawat walisongo, tidak ada syi'ir khusus yang membahas tentang kepercayaan terhadap hari akhir ini. Kepercayaan terhadap hari akhir hanya terdapat pada penggalan-penggalan syi'ir tertentu yang tergabung dengan Syi'ir yang lain. Misalnya, penggalan Syi'ir ke-35 (Lakar Terro) yang menggambarkan keinginan untuk berkumpul bersama Nabi di akhirat atau hari setelah kematian atau penggalan syi'ir ke-7 (Sokkor) yang menggambarkan keinginan untuk bahagian tidak hanya di dunia tetapi juga di akhirat.

\section{KESIMPULAN}

Dari penjelasan di atas dapat disimpukan sebagai berikut:

a. Jama'ah Shalawat Nariyah Walisongo di Desa Moncek Timur tidak berangkat dari ruang hampa. Kedatangan K. Muhammad Kholil As'ad ke Sumenep 2009 silam menjadi tonggak awal jama'ah berdiri. Secara sosiologis, tradisi masyarakat Moncek Timur sebagaimana masyarakat Madura pada umumnya yang terbiasa dengan jama'ahjama'ah keagamaan menjadikan Jama'ah Shalawat Nariyah Walisongo mudah diterima oleh masyarakat. Terlebih Jama'ah Shalawat Nariyah Walisongo bisa memberikan nuasa baru yang lebih santai namun tetap dalam nuasa keagamaan. Ketokohan K. Kholil juga tidak bisa dipungkiri telah memainkan peran penting bagi Jama'ah Shalawat Nariyah Walisongo di Desa Moncek Timur.

b. Syi'ir-syir K. Kholil yang dipakai Jama'ah Shalawat Nariyah Walisongo memiliki muatan keagamaan yang tinggi, khususnya nila- 


\section{Miftahul Arifin}

nilai yang merupakan pondasi bagi umat Islam. Syi'ir-syi'ir tersebut memiliki arti penting dalam memberikan pemahaman kepada masyarakat Moncek Timur khususnya anggota jama'ah. Penyampaian nilai-nilai menggunakan syi'ir tidak terkesan memaksakan, namun ia akan memberikan pengaruh secara perlahan melalui alam bawah sadar pendengarnya.

\section{REFERENCE}

Al Faruqi, Ismail Raji, Taubid, terj. Rahmani Astuti, Penerbit Pustaka, Bandung, 1988.

Bazz, Syaikh Abdul Aziz, terj. Shabihah Versus Aqidah Bathilah, Kantor Dakwah Komplek Industri Lama, Riyadh, 2002.

Daryanti, Jama'ah Pengajian Selapan Dusun Ngoloyo Trimulyo, Kendal (Tinjauan), 2009.

Halimi, Safrodin, Etika Dakwah Dalam Perspektif Al Qur'an, Antara Realititas Qur'ani dan Realitas Sosial, Walisongo Press, Semarang, 2008.

Hidayati, Tatik, Kompolan: Kontestasi Tradisi Perempuan Madura, Jurnal KARSA, Vol. 19 No. 2 Tahun 2011.

Ilyas, Yunahar, Kuliah Aqidah Islam, LPPI, Yogyakarta, 1993).

Jamil, Muhsin, Syi'iran Transmisi Ajaran Islam di Jawa, Walisongo Press, Semarang, 2010.

Muhni, Djuretna A. Imam, Moral dan Religi, Kanisius, Yogyakarta 1994. 
Membumikan Akidah Melalui Syi'ir: Study Nilai-Nilai Akidah dalam Syi'ir Jama'ah Shalawat Nariyah Walisongo Desa Moncek Timur Lenteng Sumenep Madura

Lexy, Moleorg J., Metode Penilitian Kualitatif dan Kuantitatif, Remaja Rosdakarya, Bandung, 2000.

Mussaif, Muhammad Muzakka, Memanfaatkan Tradisi Lisan, 2008.

Rathomi, Mohammad Abdai, Aqidah Islam, Pola Hidup Manusia Beriman, terj. Assyyid Sabiq, Al-Aqiidah Al-Islamiyah, Ikatan Penerbit Indonesia (IKPI), Bandung, 1982.

Rustandi, Aton, Belajar dari Syi'iran: Art and Multicutural, Recent MediaYayasan Akar Rumput, Semarang, 2007.

Sabiq, Sayyid, Aqidah Islam, CV Diponegoro, Bandung, 1992.

Suma, H. Muhammad Amin, Ulumul Qur'an, Rajawali Press, Jakarta 2013.

Surahmad, Winarno, Pengantar Penelitian Ilmiah (Dasar Metode Teknik), Tarsito, Bandung, 1980.

Majalah Nabdlatul Ulama, Aula edisi XXXVI Desember 2014. 